\title{
Ocorrência de animais persistentemente infectados pelo vírus da diarréia viral bovina em rebanhos bovinos nos Estados de Minas Gerais e São Paulo'
}

\author{
Fabio C. Dias ${ }^{2}$, Kerlei C. Médiciª, Bruna Alexandrino², Andréa S.R. \\ Medeiros $^{2}$, Amauri A. Alfieri ${ }^{3}$ e Samir I. Samara ${ }^{2}$
}

\begin{abstract}
Dias F.C., Médici K.C., Alexandrino B., Medeiros A.S.R., Alfieri A.A. \& Samara S.I. 2010. [Occurrence of persistently infected animals with bovine viral diarrhoea virus in cattle herds from the states of Minas Gerais and São Paulo, Brazil.] Ocorrência de animais persistentemente infectados pelo vírus da diarréia viral bovina em rebanhos bovinos nos Estados de Minas Gerais e São Paulo. Pesquisa Veterinária Brasileira 30(11):933-939. Departamento de Medicina Veterinária Preventiva e Reprodução Animal, Faculdade de Ciências Agrárias e Veterinárias, Universidade Estadual Paulista, Via de Acesso Prof. Paulo Donato Castellane s/n, Vila Industrial, Jaboticabal, SP 14884-900, Brazil. E-mail: fabiocadi@ yahoo.com.br

The research on persistently infected $(\mathrm{PI})$ animals with bovine viral diarrhoea virus (BVDV) was conducted in 26 cattle herds, which were not BVDV vaccinated, located in the states of Minas Gerais and São Paulo, Brazil. Using a sampling strategy, five samples of blood were collected from 6 to 12-month-old calves of each herd, and the blood sera were tested by virusneutralization test (VN) to BVDV-1 and BVDV-2. The herds that had at least three out of five samples reacting to one of the genotypes of BVDV and antibody titers greater than 128 were selected to PI animals research. In three of the herds that matched the before-mentioned criteria, paired blood samples were collected from all its individuals considering a collection interval of 30 days. The blood sera of these samples were VN tested against BVDV-1 and BVDV-2. In samples not reacting to at least one of the BVDV genotypes and also in those collected from calves of less than six months of age, virus research was undertaken by reverse transcription polymerase chain reaction (RT-PCR). From the examined herds, two PI animals were detected in paired samples obtained from a herd located in the state of Minas Gerais.
\end{abstract}

INDEX TERMS: Bovine viral diarrhoea virus, persistently infected animal, BVDV-1, BVDV-2, RTPCR, virusneutralization.

RESUMO.- A pesquisa de animais persistentemente infectados (PI) pelo vírus da diarréia viral bovina (BVDV) foi realizada em 26 rebanhos bovinos, não vacinados contra o BVDV, localizados nos Estados de Minas Gerais e São Paulo, Brasil. Utilizando uma estratégia de amostragem,

\footnotetext{
${ }^{1}$ Recebido em 12 de abril de 2010.

Aceito para publicação 23 de julho de 2010.

2 Departamento de Medicina Veterinária Preventiva e Reprodução Animal, Faculdade de Ciências Agrárias e Veterinárias (FCAV), Universidade Estadual Paulista (Unesp), Via de Acesso Prof. Paulo Donato Castellane s/n, Vila Industrial, Jaboticabal, SP 14884-900, Brasil. *Autor para correspondência: fabiocadi@yahoo.com.br

${ }^{3}$ Laboratório de Virologia Animal, Departamento de Medicina Veterinária Preventiva, Centro de Ciências Agrárias (CCA), Universidade Estadual de Londrina (UEL), Rodovia Celso Garcia Cid (PR 445) Km 380, Cx. Postal 6001, Londrina, PR 86051-990, Brasil.
}

de cada rebanho foram obtidas cinco amostras de sangue de bezerros, entre 6 e 12 meses de idade, e os soros sanguíneos foram submetidos ao teste de virusneutralização (VN) para o BVDV-1 e o BVDV-2. Os rebanhos que apresentaram pelo menos três das cinco amostras reagentes a um dos genótipos do BVDV, e com títulos de anticorpos superiores a 128, foram selecionados para a pesquisa de animais PI. Em três rebanhos que apresentaram tal condição, foram colhidas amostras pareadas de sangue de todos os bovinos do rebanho, com intervalo de 30 dias entre as colheitas, e o soro sanguíneo foi submetido ao teste de VN para o BVDV-1 e o BVDV-2. Nas amostras não reagentes a pelo menos um dos genótipos do BVDV e naquelas provenientes de bovinos com menos de seis meses de idade, realizou-se a pesquisa do BVDV pela reação em cadeia da polimerase precedida pela transcrição reversa 
(RT-PCR). Dos rebanhos analisados, foram detectados dois animais PI a partir de amostras obtidas nas colheitas pareadas provenientes de um rebanho localizado no Estado de Minas Gerais.

TERMOS DE INDEXAÇÃO: Vírus da diarréia viral bovina, animal persistentemente infectado, BVDV-1, BVDV-2, RT-PCR, virusneutralização.

\section{INTRODUÇÃO}

O termo "vírus da diarréia viral bovina (BVDV)" refere-se a um diverso grupo de RNA-vírus, classificados em duas diferentes espécies (BVDV-1 e BVDV-2) pertencentes à família Flaviviridae e ao gênero Pestivirus. São vírus que podem existir em dois diferentes biótipos, citopatogênico (CP) e não citopatogênico (NCP), os quais variam na virulência, podendo apresentar-se tanto na forma avirulenta até aquela altamente virulenta (Ridpath 2010). Dentre os vírus que infectam bovinos, o BVDV é aquele que apresenta a patogenia mais complexa (Deregt 2005).

O principal fator na disseminação natural do BVDV é a existência do animal persistentemente infectado (PI). A infecção do feto bovino com o biótipo NCP antes do desenvolvimento da competência imunológica, isto é, até 125 dias de gestação, pode resultar na geração de um animal que apresenta a infecção persistente pelo BVDV por toda sua vida. Nessa fase da gestação, o sistema imunológico do feto é imaturo e as proteínas virais são reconhecidas erroneamente como próprias, o que torna o animal imunologicamente tolerante ao BVDV (Dubovi 1998). A geração de animais $\mathrm{PI}$ é mais frequente quando a infecção fetal ocorre entre 30 e 90 dias de gestação, podendo ser estabelecida tanto pelo BVDV-1 quanto pelo BVDV-2 (Lieber-Tenorio 2005). O animal PI é considerado a principal fonte de infecção do BVDV porque elimina por toda sua vida uma grande quantidade de vírus em secreções e excreções (Houe 1995).

Muitos animais PI podem ser clinicamente saudáveis, embora a sua expectativa de vida seja baixa (Houe 1993), pois todos apresentam o risco de desenvolver a doença das mucosas (MD) (Brownlie 1990). Alguns podem até alcançar a idade adulta e, caso isso ocorra com fêmeas PI, a sua progênie também será PI (Baker 1987). A taxa de letalidade dos bezerros $\mathrm{PI}$ é superior a $50 \%$ no primeiro ano de vida, principalmente porque muitos deles nascem prematuros, fracos, letárgicos ou apresentam algum tipo de malformação congênita. Alguns bezerros morrem poucos dias ou até mesmo algumas horas após o nascimento e, aqueles que sobrevivem, podem apresentar atraso no crescimento e baixa resistência a outras enfermidades (Bolin 1990).

Como a prevalência dos animais $\mathrm{PI}$ é baixa nos rebanhos e os sinais clínicos não são suficientes para a caracterização desses animais, foram desenvolvidas estratégias de amostragem para o diagnóstico dos rebanhos infectados com o BVDV (Houe 1992, Houe 1994, Pillars \& Grooms 2002). A pesquisa sorológica pode ser utilizada para determinar a existência ou não de bovinos PI nos rebanhos, pois a presença de um bovino reagente num rebanho não vacinado é uma evidência suficiente que caracteriza a exposição da população ao BVDV (Smith \& Grotelueschen 2004).

$\mathrm{Na}$ presença de um animal $\mathrm{PI}$, a infecção pelo BVDV dissemina-se rapidamente para a maioria dos animais do rebanho, induzindo altos títulos de anticorpos neutralizantes. Essa característica é utilizada para a identificação de rebanhos com animais $\mathrm{PI}$, por meio da determinação de títulos de anticorpos no soro sanguíneo de animais denominados sentinelas ou pela detecção de anticorpos no leite de conjunto (Seki et al. 2006).

A identificação e a remoção de bovinos PI são medidas essenciais para a prevenção e o controle da diarréia viral bovina (BVD) (Brock 2003). Apesar de ser baixa a prevalência desses animais nos rebanhos, a sua presença reflete-se num grande impacto econômico. Sendo assim, o objetivo deste trabalho foi pesquisar a ocorrência de animais PI pelo BVDV em rebanhos bovinos localizados nos Estados de Minas Gerais e São Paulo, Brasil.

\section{MATERIAL E MÉTODOS}

\section{Amostragem}

Empregou-se a metodologia adotada por Pillars \& Grooms (2002), por meio da pesquisa de anticorpos em amostras de sangue de cinco bezerros não vacinados contra o BVDV com idade entre 6 e 12 meses. Em tal metodologia, um rebanho foi considerado reagente quando três de cinco bezerros apresentaram títulos de anticorpos neutralizantes superiores a 128 frente a um genótipo do vírus, já que as amostras eram submetidas à virusneutralização (VN) tanto para o BVDV-1 quanto para o BVDV-2. Por outro lado, quando três de cinco bezerros apresentavam títulos menores do que 64 para ambos os genótipos, o rebanho era classificado como negativo.

\section{Amostras}

Foram colhidas, aleatoriamente, amostras de sangue de cinco bovinos com idade entre 6 e 12 meses, em 26 rebanhos, sendo seis deles localizados no Estado de Minas Gerais, respectivamente nos municípios de Machado, Poço Fundo e São Gonçalo do Sapucaí, e os demais rebanhos localizados no Estado de São Paulo, respectivamente nos municípios de Jaboticabal, Monte Alto, Sertãozinho, São Carlos, Guariba, Pedregulho, São José do Rio Preto, Cristais Paulista, Buritizal e Rifaina.

Os rebanhos pesquisados não adotavam a prática de vacinação contra o BVDV, eram de exploração leiteira ou de corte e o número total de bovinos variava de 20 a 480 . As amostras de sangue foram colhidas em tubos siliconizados "vacutainer" $\mathrm{BD}^{\circledR}$ e, depois de colhidas, foram centrifugadas a $1.080 x g$. De cada amostra, foram obtidas duas alíquotas contendo $1,5 \mathrm{~mL}$ de soro sanguíneo que foram assim destinadas: uma amostra para o teste contra o BVDV-1 e outra para o teste contra o BVDV-2. As amostras foram armazenadas em "freezer", a $-20^{\circ} \mathrm{C}$, até o momento do uso.

\section{Teste sorológico}

Todas as amostras foram submetidas ao teste de VN para a pesquisa de anticorpos neutralizantes contra o BVDV-1 e 
contra o BVDV-2 (OIE, 2008). No teste de VN, foram utilizadas células epiteliais de rim bovino da linhagem "Madin Darby bovine kidney" (MDBK), mantidas em meio Eagle MEM ("Minimal Essential Medium") Gibco ${ }^{\circledR}$, suplementadas com $10 \%$ de soro fetal bovino (SFB) Cultilab ${ }^{\circledR}$ livre de Pestivirus e de anticorpos para o BVDV, e empregadas as cepas CP do BVDV1 (Singer) e do BVDV-2 (VS-253). As amostras de soro sanguíneo, antes de serem testadas, foram previamente inativadas a $56^{\circ} \mathrm{C}$ por 30 minutos. Os testes de $\mathrm{VN}$ foram realizados em placas de microtitulação descartáveis de 96 cavidades TPP ${ }^{\circledR}$, e o meio de manutenção Eagle-MEM Gibco ${ }^{\circledR}$, utilizado para as diluições das amostras de soro, era acrescido de 1\% de uma solução de penicilina (10.000UI $\left.\mathrm{mL}^{-1}\right)$ e estreptomicina (10.000ug $\mathrm{mL}^{-1}$ ) Gibco ${ }^{\circledR}$.

Para cada amostra de soro testada, foram feitas duplicatas com diluições sucessivas entre 1:10 e 1:5.120. Depois de adicionada a suspensão viral contendo 100 TCID $_{50}(50 \%$ "tissue culture infective doses") do BVDV, as microplacas foram incubadas em estufa com atmosfera de $5 \%$ de $\mathrm{CO}_{2}$ a $37^{\circ} \mathrm{C}$. Transcorridos 60 minutos, foi adicionada, em todas as cavidades das placas, uma suspensão de células MDBK contendo 300.000 células $\mathrm{mL}^{-1}$ em meio de manutenção Eagle-MEM Gibco ${ }^{\circledR}$ com $10 \%$ de SFB Cultilab ${ }^{\circledR}$. Em seguida, a placa foi novamente incubada em estufa, a $37^{\circ} \mathrm{C}$, com atmosfera de $5 \%$ de $\mathrm{CO}_{2}$ por 96 horas. Na interpretação dos resultados, foram consideradas reagentes as amostras de soro sanguíneo que promoviam neutralização de $100 \mathrm{TCID}_{50}$ do BVDV a partir da diluição 1:10. Os títulos de anticorpos foram expressos como a recíproca da maior diluição em que foi verificada a neutralização viral, e o título final foi resultante da média geométrica dos títulos - GMT (Thrusfield 1986) encontrados nas duplicatas.

\section{Pesquisa de bovinos PI}

Foram selecionados, para a pesquisa do BVDV, os rebanhos em que pelo menos três dos cinco bovinos eram reagentes ao BVDV no teste de VN, para o BVDV-1 ou para o BVDV2 , e apresentavam títulos de anticorpos iguais ou superiores a 128, de acordo com os parâmetros adotados por Pillars \& Grooms (2002). Transcorridos 20 dias em que foi realizada a amostragem e conhecidos os resultados do teste de VN, desses rebanhos, foram então colhidas amostras pareadas de sangue de toda população de bovinos, com intervalo de 30 dias entre as colheitas. Obtidas as amostras de soro sanguíneo, as mesmas foram submetidas ao teste de VN para o BVDV1 e para o BVDV-2, em duplicata e com diluições sucessivas do soro sangüíneo de 1:10 até 1:5.120. As amostras pareadas de cada bovino foram analisadas simultaneamente numa mesma placa de microtitulação, quer seja quando testadas para o BVDV-1 ou para o BVDV-2.

O teste diagnóstico empregado para a pesquisa do BVDV foi a reação em cadeia da polimerase precedida pela transcrição reversa (RT-PCR), utilizando o protocolo descrito por Pilz et al. (2005), com algumas modificações. Para tal, foram utilizadas as amostras de soro sangüíneo que não foram reagentes em pelo menos um dos testes de VN, contra o BVDV-1 ou contra o BVDV-2, e em todas as amostras, reagentes ou não, de bovinos com idade inferior a seis meses.

A extração do RNA foi realizada segundo a metodologia preconizada por Boom et al. (1990), com a utilização de partículas de sílica e isotiocianato de guanidina para a purificação de ácidos nucléicos. $\mathrm{Na}$ extração, foram utilizados $500 \mu \mathrm{L}$ do soro sanguíneo de cada amostra a ser testada e o RNA extraído foi eluído em água tratada com DEPC (dietil pirocarbonato). A RT-PCR foi realizada utilizando os oligonucleotídeos iniciadores 103 senso (5'TAG CCA TGC CCT TAG TAG GAC 3' posição genômica 103-124) e 372 antissenso (5'ACT CCA TGT GCC ATG TAC AGC 3' - posição genômica 372-392), desenhados a partir da seqüência da região não traduzida (5’UTR) do genoma viral do BVDV-1a NADL, que amplifica um produto de 290 pares de base (pb) e compartilha homologia máxima entre o BVDV-1 e o BVDV-2 (Weinstock et al. 2001).

A RT foi realizada com $9 \mu \mathrm{L}$ da suspensão contendo o RNA e 20pmol do oligonucleotídeo iniciador antissenso 372, que foi desnaturado a $97^{\circ} \mathrm{C}$ por 5 minutos, e imediatamente colocada em banho de gelo por 5 minutos. Transcorrido esse período, em cada amostra foram adicionados $8 \mu \mathrm{L}$ do "mix" RT contendo água ultrapura autoclavada, PCR "buffer" $10 x$ Invitrogen ${ }^{\text {TM }}$ Life Technology $(200 \mathrm{mM}$ tris- $\mathrm{HCl} \mathrm{pH} 8,4 ; 500 \mathrm{mM}$ $\mathrm{KCl}), 0,25 \mathrm{mM}$ de cada desoxirribonucleotídeo trifosfatado (dNTP) Invitrogen ${ }^{\mathrm{TM}}$ Life Technology, $1,5 \mathrm{mM}$ de $\mathrm{MgCl}_{2}$ Invitrogen ${ }^{\mathrm{TM}}$ Life Technology e 60 unidades da enzima transcriptase reversa "Moloney Murine Leukemia Virus Reverse Transcriptase" (M-MLV-RT) Invitrogen ${ }^{\mathrm{TM}}$ Life Technology, perfazendo assim um volume final de $20 \mu \mathrm{L}$. Após a homogeneização, a síntese do cDNA foi realizada a $42^{\circ} \mathrm{C}$ por 30 minutos, seguido por uma etapa de 5 minutos a $95^{\circ} \mathrm{C}$ para a inativação da enzima M-MLV-RT.

A PCR foi realizada com $5 \mu \mathrm{L}$ do cDNA e $45 \mu \mathrm{L}$ do "mix" PCR constituído por água ultrapura autoclavada, PCR "buffer" 10x (200mM tris- $\mathrm{HCl} \mathrm{pH} 8,4 ; 500 \mathrm{mM} \mathrm{KCl}), 0,25 \mathrm{mM}$ de cada dNTP, $1,5 \mathrm{mM}$ de $\mathrm{MgCl}_{2}$, 20pmol de cada oligonucleotídeo iniciador (senso 103 e antissenso 372) e 2,5 unidades da enzima "Taq Platinum DNA polymerase" Invitrogen TM Life Technology, totalizando um volume final de $50 \mu \mathrm{L}$ por amostra. As amostras de cDNA, juntamente com o "mix" PCR, foram homogeneizados e a reação foi realizada em termociclador (PTC - 200, MJ Research Co. Water Town, Ma, USA) numa etapa a $94^{\circ} \mathrm{C}$ por 2 minutos; 35 ciclos de 1 minuto a $94^{\circ} \mathrm{C}$ (desnaturação), 30 segundos a $59^{\circ} \mathrm{C}$ (anelamento) e 1 minuto a $72^{\circ} \mathrm{C}$ (extensão); e um ciclo a $72^{\circ} \mathrm{C}$ por 7 minutos (extensão final).

Os produtos da PCR foram analisados pela eletroforese em gel de agarose a $2 \%$ Invitrogen $^{\mathrm{TM}}$ Life Technology com brometo de etídeo $(0,5 \mathrm{mg} / \mathrm{mL})$, em tampão TBE pH 8,4 (89mM tris; $89 \mathrm{mM}$ ácido bórico; $2 \mathrm{mM}$ EDTA), sob voltagem constante (100V) e durante aproximadamente 60 minutos. Em cada gel foram reservadas duas canaletas para os controles positivos (BVDV-1 e BVDV-2), aplicados no mesmo volume das amostras, e uma canaleta para o controle negativo (água ultrapura autoclavada). Transcorrido esse período, o gel foi visualizado em um aparelho fotodocumentador BioRad ${ }^{\circledR}$ sob luz ultravioleta e fotodocumentado em sistema digital "Electrophoresis Documentation and Analysis System" 290 KODAK $^{\circledR}$.

\section{RESULTADOS}

Nos testes de VN realizados em cinco amostras de soro sangüíneo de bovinos com 6 a 12 meses de idade (Quadro 1), em 26 rebanhos localizados nos Estados de Minas Gerais e de São Paulo, nove rebanhos (1, 2, 4, 5, 7, 16, 17,20 e 21) apresentaram bovinos reagentes ao BVDV-1. Desse total, quatro rebanhos $(5,7,16$ e 20) apresentaram apenas um bovino reagente, um rebanho (21) apresentou dois bovinos reagentes, três rebanhos (1, 2 e 17) apresen- 


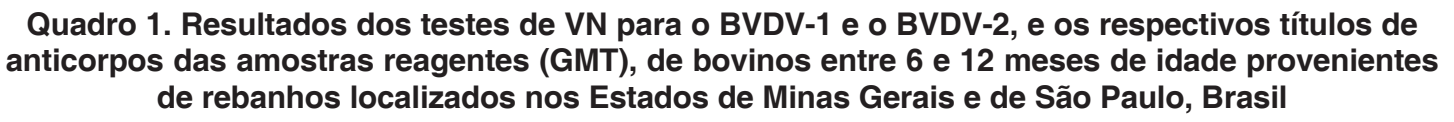

\begin{tabular}{|c|c|c|c|c|c|c|c|c|c|c|c|c|}
\hline \multicolumn{3}{|c|}{ Identificação } & \multicolumn{10}{|c|}{ Resultados dos testes de VN } \\
\hline \multirow[t]{2}{*}{ Rebanho } & \multirow[t]{2}{*}{ Localização } & \multirow[t]{2}{*}{ Estado } & \multicolumn{5}{|c|}{$\begin{array}{c}\text { BVDV-1 } \\
\text { Amostras }\end{array}$} & \multicolumn{5}{|c|}{$\begin{array}{c}\text { BVDV-2 } \\
\text { Amostras }\end{array}$} \\
\hline & & & 1 & 2 & 3 & 4 & 5 & 1 & 2 & 3 & 4 & 5 \\
\hline 1 & Machado & $M G$ & 160 & 160 & $\mathrm{nr}$ & 80 & 320 & 80 & 60 & $\mathrm{nr}$ & 160 & 20 \\
\hline 2 & S. G. do Sapucaí & MG & 40 & 40 & 320 & $\mathrm{nr}$ & 80 & 320 & 40 & 3.840 & 80 & 226 \\
\hline 3 & S. G. do Sapucaí & MG & $\mathrm{nr}$ & $\mathrm{nr}$ & $\mathrm{nr}$ & $\mathrm{nr}$ & $\mathrm{nr}$ & $\mathrm{nr}$ & $\mathrm{nr}$ & $\mathrm{nr}$ & 14 & $\mathrm{nr}$ \\
\hline 4 & Poço Fundo & MG & 80 & 640 & 1810 & 640 & 640 & 160 & 1.280 & 2.560 & 1.810 & 1.280 \\
\hline 5 & Poço Fundo & MG & $\mathrm{nr}$ & $\mathrm{nr}$ & $\mathrm{nr}$ & 20 & $\mathrm{nr}$ & $\mathrm{nr}$ & $\mathrm{nr}$ & 20 & 40 & $\mathrm{nr}$ \\
\hline 6 & Machado & $M G$ & $\mathrm{nr}$ & $\mathrm{nr}$ & $\mathrm{nr}$ & $\mathrm{nr}$ & $\mathrm{nr}$ & $\mathrm{nr}$ & $\mathrm{nr}$ & $\mathrm{nr}$ & $\mathrm{nr}$ & $\mathrm{nr}$ \\
\hline 7 & S. J. do Rio Preto & SP & $\mathrm{nr}$ & $\mathrm{nr}$ & 10 & $\mathrm{nr}$ & $\mathrm{nr}$ & $\mathrm{nr}$ & $\mathrm{nr}$ & $\mathrm{nr}$ & $\mathrm{nr}$ & $\mathrm{nr}$ \\
\hline 8 & Jaboticabal & SP & $\mathrm{nr}$ & $\mathrm{nr}$ & $\mathrm{nr}$ & $\mathrm{nr}$ & $\mathrm{nr}$ & $\mathrm{nr}$ & $\mathrm{nr}$ & $\mathrm{nr}$ & $\mathrm{nr}$ & $\mathrm{nr}$ \\
\hline 9 & Sertãozinho & SP & $\mathrm{nr}$ & $\mathrm{nr}$ & $\mathrm{nr}$ & $\mathrm{nr}$ & $\mathrm{nr}$ & $\mathrm{nr}$ & $\mathrm{nr}$ & $\mathrm{nr}$ & $\mathrm{nr}$ & $\mathrm{nr}$ \\
\hline 10 & São Carlos & SP & $\mathrm{nr}$ & $\mathrm{nr}$ & $\mathrm{nr}$ & $\mathrm{nr}$ & $\mathrm{nr}$ & $\mathrm{nr}$ & $\mathrm{nr}$ & $\mathrm{nr}$ & $\mathrm{nr}$ & $\mathrm{nr}$ \\
\hline 11 & São Carlos & SP & $\mathrm{nr}$ & $\mathrm{nr}$ & $\mathrm{nr}$ & $\mathrm{nr}$ & $\mathrm{nr}$ & $\mathrm{nr}$ & $\mathrm{nr}$ & $\mathrm{nr}$ & $\mathrm{nr}$ & $\mathrm{nr}$ \\
\hline 12 & Jaboticabal & SP & $\mathrm{nr}$ & $\mathrm{nr}$ & $\mathrm{nr}$ & $\mathrm{nr}$ & $\mathrm{nr}$ & $\mathrm{nr}$ & $\mathrm{nr}$ & $\mathrm{nr}$ & $\mathrm{nr}$ & $\mathrm{nr}$ \\
\hline 13 & Jaboticabal & SP & $\mathrm{nr}$ & $\mathrm{nr}$ & $\mathrm{nr}$ & $\mathrm{nr}$ & $\mathrm{nr}$ & $\mathrm{nr}$ & $\mathrm{nr}$ & $\mathrm{nr}$ & $\mathrm{nr}$ & $\mathrm{nr}$ \\
\hline 14 & Guariba & SP & $\mathrm{nr}$ & $\mathrm{nr}$ & $\mathrm{nr}$ & $\mathrm{nr}$ & $\mathrm{nr}$ & $\mathrm{nr}$ & $\mathrm{nr}$ & $\mathrm{nr}$ & $\mathrm{nr}$ & $\mathrm{nr}$ \\
\hline 15 & Guariba & SP & $\mathrm{nr}$ & $\mathrm{nr}$ & $\mathrm{nr}$ & $\mathrm{nr}$ & $\mathrm{nr}$ & $\mathrm{nr}$ & $\mathrm{nr}$ & $\mathrm{nr}$ & $\mathrm{nr}$ & $\mathrm{nr}$ \\
\hline 16 & Guariba & SP & 10 & $\mathrm{nr}$ & $\mathrm{nr}$ & $\mathrm{nr}$ & $\mathrm{nr}$ & $\mathrm{nr}$ & $\mathrm{nr}$ & $\mathrm{nr}$ & $\mathrm{nr}$ & $\mathrm{nr}$ \\
\hline 17 & Pedregulho & SP & 640 & 20 & 226 & $\mathrm{nr}$ & 640 & 80 & $\mathrm{nr}$ & 10 & $\mathrm{nr}$ & 80 \\
\hline 18 & Pedregulho & SP & $\mathrm{nr}$ & $\mathrm{nr}$ & $\mathrm{nr}$ & $\mathrm{nr}$ & $\mathrm{nr}$ & $\mathrm{nr}$ & $\mathrm{nr}$ & $\mathrm{nr}$ & $\mathrm{nr}$ & $\mathrm{nr}$ \\
\hline 19 & Cristais Paulista & SP & $\mathrm{nr}$ & $\mathrm{nr}$ & $\mathrm{nr}$ & $\mathrm{nr}$ & $\mathrm{nr}$ & $\mathrm{nr}$ & $\mathrm{nr}$ & $\mathrm{nr}$ & $\mathrm{nr}$ & $\mathrm{nr}$ \\
\hline 20 & Buritizal & SP & $\mathrm{nr}$ & $\mathrm{nr}$ & $\mathrm{nr}$ & 640 & $\mathrm{nr}$ & $\mathrm{nr}$ & $\mathrm{nr}$ & 40 & 905 & $\mathrm{nr}$ \\
\hline 21 & Pedregulho & SP & $\mathrm{nr}$ & 320 & $\mathrm{nr}$ & $\mathrm{nr}$ & 10 & $\mathrm{nr}$ & 40 & $\mathrm{nr}$ & $\mathrm{nr}$ & $\mathrm{nr}$ \\
\hline 22 & Buritizal & SP & $\mathrm{nr}$ & $\mathrm{nr}$ & $\mathrm{nr}$ & $\mathrm{nr}$ & $\mathrm{nr}$ & $\mathrm{nr}$ & $\mathrm{nr}$ & $\mathrm{nr}$ & 10 & $\mathrm{nr}$ \\
\hline 23 & Buritizal & SP & $\mathrm{nr}$ & $\mathrm{nr}$ & $\mathrm{nr}$ & $\mathrm{nr}$ & $\mathrm{nr}$ & $\mathrm{nr}$ & $\mathrm{nr}$ & $\mathrm{nr}$ & $\mathrm{nr}$ & $\mathrm{nr}$ \\
\hline 24 & Cristais Paulista & SP & $\mathrm{nr}$ & $\mathrm{nr}$ & $\mathrm{nr}$ & $\mathrm{nr}$ & $\mathrm{nr}$ & $\mathrm{nr}$ & $\mathrm{nr}$ & $\mathrm{nr}$ & $\mathrm{nr}$ & $\mathrm{nr}$ \\
\hline 25 & Monte Alto & SP & $\mathrm{nr}$ & $\mathrm{nr}$ & $\mathrm{nr}$ & $\mathrm{nr}$ & $\mathrm{nr}$ & $\mathrm{nr}$ & $\mathrm{nr}$ & $\mathrm{nr}$ & $\mathrm{nr}$ & $\mathrm{nr}$ \\
\hline 26 & Rifaina & SP & $\mathrm{nr}$ & $\mathrm{nr}$ & $\mathrm{nr}$ & $\mathrm{nr}$ & $\mathrm{nr}$ & $\mathrm{nr}$ & $\mathrm{nr}$ & $\mathrm{nr}$ & $\mathrm{nr}$ & $\mathrm{nr}$ \\
\hline
\end{tabular}

taram quatro bovinos reagentes e um rebanho (4) apresentou cinco bovinos reagentes. Para o BVDV-2, também foram encontrados bovinos reagentes no teste de $\mathrm{VN}$ em nove rebanhos (1, 2, 3, 4, 5, 17, 20, 21 e 22). Desse total, três rebanhos $(3,21$ e 22$)$ apresentaram apenas um bovino reagente, dois rebanhos (5 e 20) apresentaram dois bovinos reagentes, um rebanho (17) apresentou três bovinos reagentes, um rebanho (1) apresentou quatro bovinos reagentes e dois rebanhos (2 e 4) apresentaram cinco bovinos reagentes. Os rebanhos 1, 2, 4, 5, 17, 20 e 21 possuíam bovinos reagentes tanto ao BVDV-1 quanto ao BVDV-2. Nos rebanhos 7 e 16 foram encontrados bovinos reagentes apenas ao BVDV-1, e nos rebanhos 3 e 22, apenas ao BVDV-2.

Sendo assim, foram selecionados para a pesquisa os rebanhos dos quais pelo menos três dos cinco bovinos eram reagentes, ao BVDV-1 ou ao BVDV-2, e apresentavam títulos de anticorpos iguais ou superiores a 128 (Pillars \& Grooms 2002). Desse modo, quatro rebanhos foram selecionados (1, 2, 4 e 17), pois possuíam bovinos reagentes nos referidos parâmetros adotados. Os rebanhos $1 \mathrm{e}$ 17 apresentaram essa condição quando testados para o BVDV-1, o rebanho 2 para o BVDV-2, e o rebanho 4 apresentou resultados dentro dos parâmetros adotados quando testado para ambos os genótipos do BVDV.

Dos rebanhos selecionados, foram colhidas amostras pareadas de todos os bovinos nos rebanhos 1 e 4 , localizados no Estado de Minas Gerais, e no rebanho 17, localizado no Estado de São Paulo. No rebanho 2 não foi possível a realização das colheitas porque o proprietário não concedeu a autorização. No total, foram colhidas 1.005 amostras de sangue referentes às duas colheitas realizadas, sendo 669 amostras pertencentes a 341 bovinos do rebanho 1, 148 amostras pertencentes a 76 bovinos do rebanho 4 e 188 amostras pertencentes a 95 bovinos do rebanho 17. Em alguns bovinos não foi possível a colheita de amostras pareadas, pois na ocasião da segunda coIheita haviam morrido ou tinham sido descartados. Por outro lado, foram obtidas, apenas na segunda colheita, amostras de bezerros que haviam nascido naquele intervalo.

A RT-PCR foi realizada nas amostras de soro sangüíneo não reagentes ao BVDV-1 e ao BVDV-2, nas amostras em que pelo menos uma delas não foi reagente ao BVDV-1 ou ao BVDV-2 e também em todas as amostras, reagentes ou não, de bovinos com menos de seis meses de idade. A maioria das amostras dos três rebanhos pesquisados que não foram reagentes ao BVDV-1 também não foram reagentes ao BVDV-2. Dessa maneira, foram analisadas 277 amostras de soro sangüíneo, sendo 184 amostras provenientes do rebanho 1, 21 amostras do rebanho 4 e 72 amostras do rebanho 17.

A análise pela RT-PCR resultou na amplificação de pro- 


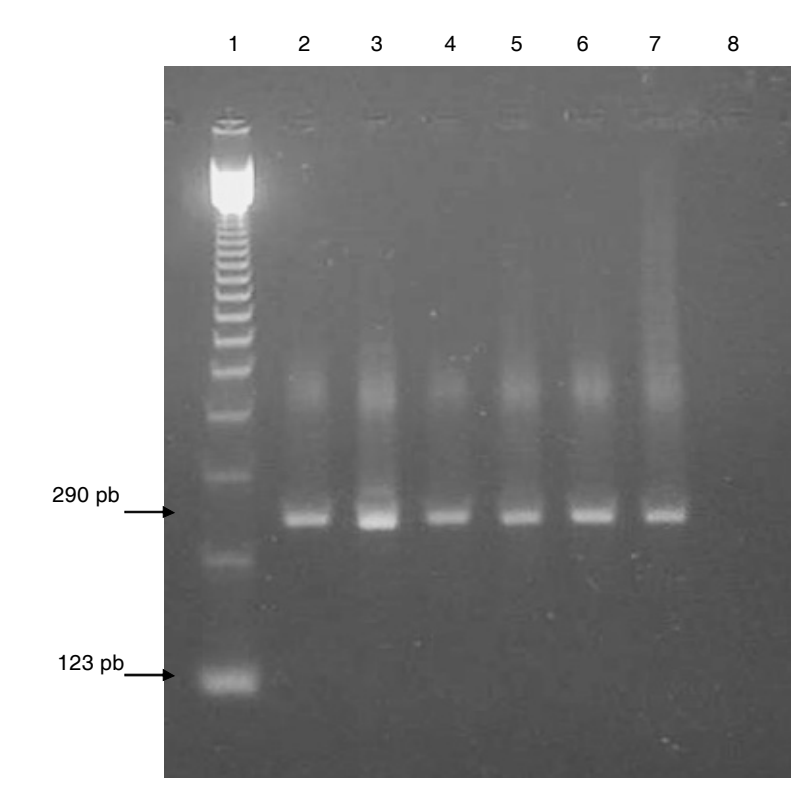

Fig.1. Análise para a detecção do BVDV, por eletroforese em gel de agarose $2 \%$ com brometo de etídeo, dos produtos (290 pb) amplificados pela RT-PCR em amostras pareadas de soro sanguíneo do rebanho 4. (1) Marcador de peso molecular DNA "ladder" 123 pb Invitrogen ${ }^{\circledR}$; (2) estirpe citopatogênica BVDV-1 Singer; (3) estirpe citopatogênica BVDV-2 VS-253; (4) amostra 4/58 A; (5) amostra 4/58 B; (6) amostra 4/72 A; (7) amostra 4/72 B; (8) controle negativo, água ultrapura autoclavada.

dutos com $290 \mathrm{pb}$ em amostras pareadas provenientes de dois bovinos do rebanho 4 (amostras 4/58 A, 4/58 B, 4/72 A e 4/72 B) (Fig. 1). Para as amostras oriundas dos rebanhos 1 e 17, não ocorreu a amplificação de produtos na RT-PCR.

\section{DISCUSSÃO}

A análise pela RT-PCR resultou na detecção do genoma do BVDV em amostras pareadas provenientes de dois bovinos do rebanho 4, localizado no Estado de Minas Gerais. Essas amostras eram de animais com idade inferior a seis meses e na VN não foram reagentes ao BVDV-1 e nem ao BVDV-2, caracterizando assim dois animais PI, pois a confirmação desses animais somente é realizada pela detecção do vírus em amostras pareadas colhidas no intervalo entre 3 e 4 semanas (Brock 1995, Sandvick 1999).

Dentre 26 rebanhos, foram detectados animais $\mathrm{PI}$ em apenas um deles. A diferente condição existente nas infecções pelo BVDV, na qual a presença de animais reagentes não significa a presença do vírus num rebanho, além da baixa prevalência dos animais PI nos rebanhos infectados, torna difícil a detecção dos rebanhos verdadeiramente infectados (Houe 1995, Smith \& Grotelueschen 2004). No entanto, neste estudo, todos os rebanhos foram submetidos à amostragem sem levar em consideração a suspeita ou não da presença da BVD e somente em três deles foi realizada a pesquisa de animais $\mathrm{PI}$.

Para Houe (1995), a prevalência de animais PI em rebanhos infectados encontra-se no intervalo entre $0,5 \% \mathrm{e}$
$2 \%$, podendo, inclusive, ser até duas vezes maior quando esses animais são detectados entre os bovinos jovens. É nessa última condição que se insere a prevalência de animais PI encontrada no rebanho 4, pois os animais PI tinham idade inferior a seis meses. Como nesse rebanho foram detectados dois animais PI e, na ocasião da colheita das amostras pareadas no rebanho 4 o número total de bovinos existentes era 76, a prevalência encontrada desses animais foi $2,63 \%$.

Quando todos os bovinos do rebanho 4 foram submetidos às colheitas pareadas de soro sangüíneo, os animais PI (amostras 4/58 e 4/72) tinham entre 4 e 5 meses de idade, eram bezerros saudáveis e não apresentavam diferenças no desenvolvimento em relação aos demais bovinos da mesma faixa etária (Houe 1993). Porém, um desses bezerros (amostra 4/58), três meses depois de realizada a última colheita, apresentou sinais clínicos de incoordenação motora e de enfraquecimento progressivo seguido do óbito. Os sinais clínicos apresentados por esse bezerro poderiam ser resultantes de outra etiologia e também poderiam estar relacionados à baixa resistência imunológica, características comuns aos animais PI (Bolin 1990), o que contribui para que a taxa de letalidade desses animais seja alta no primeiro ano de vida (Baker 1987). Já o outro bezerro (amostra 4/72) teve o desenvolvimento normal, mas segundo o proprietário, sempre aquém dos demais animais do mesmo lote.

A utilização de estratégias de amostragem para a pesquisa de rebanhos infectados pelo BVDV é uma alternativa prática e econômica para a verificação do estado sanitário de um rebanho não vacinado contra o BVDV (Smith \& Grotelueschen 2004). Neste trabalho, a estratégia utilizada foi a pesquisa de anticorpos neutralizantes em animais sentinelas, no caso bezerros com idade entre 6 e 12 meses. Dessa maneira, rebanhos de qualquer aptidão puderam ser submetidos à amostragem (Seki et al. 2006).

A pesquisa de anticorpos realizada em bezerros sentinelas mostra se a transmissão do vírus está ocorrendo dentro do rebanho, sendo que a vantagem dessa estratégia é a eficiência do diagnóstico, já que a detecção de reagentes indica a transmissão do vírus envolvendo animais PI ou animais transitoriamente infectados (TI), ou seja, aqueles que apresentam a infecção aguda (Smith \& Grotelueschen 2004).

Para Pillars \& Grooms (2002), a utilização de cinco amostras de sangue de bezerros sentinelas consistiu num método válido para a identificação de rebanhos leiteiros com animais $\mathrm{PI}$, independentemente do número de animais existentes no rebanho. Segundo os autores, cuja mesma metodologia de amostragem foi empregada neste estudo, o número de amostras $(n=5)$ estabelecido nessa amostragem foi obtido utilizando um programa estatístico que considerou a quantidade de rebanhos com animais $\mathrm{PI}$ igual à quantidade de rebanhos sem animais $\mathrm{PI}$, conforme lógica de fatores de risco para qualquer infecção com o BVDV.

O emprego de estratégias de amostragem com a utilização de amostras de sangue obtidas de poucos animais 
do rebanho foi objeto de estudo em outras pesquisas. Houe (1992) propôs um método para identificar rebanhos leiteiros com animais PI por meio da análise sorológica de cinco bezerros não vacinados com idade entre 6 e 18 meses, baseando-se no fato de que a alta prevalência de bezerros reagentes forneceria uma evidência indireta da existência de pelo menos um animal PI no rebanho. Para este autor, pôde ser possível distinguir rebanhos com e sem animais PI utilizando amostras de sangue de poucos animais do rebanho.

O estudo, também realizado por Houe (1994), teve como objetivo verificar se a detecção de anticorpos contra o BVDV em 10 amostras de animais entre 8 e 18 meses de idade poderia ser utilizada como um método seguro para definir o estado sanitário para a BVD em rebanhos leiteiros. Os resultados confirmaram que a investigação a partir de poucas amostras consistiu num método seguro para predizer a presença ou ausência de animais PI no rebanho, pois a maioria das amostras era reagente nos rebanhos altamente infectados e, em rebanhos com baixas taxas de prevalência, o número de amostras reagentes era menor ou igual a três.

Outra estratégia de amostragem, como a pesquisa de anticorpos em leite de conjunto, pode ser utilizada para identificar rebanhos leiteiros expostos ao BVDV, desde que os mesmos não utilizem a vacinação (Dias \& Samara 2003). As amostras de leite de conjunto podem também ser utilizadas para a pesquisa do BVDV pela técnica da RT-PCR. Comparado ao diagnóstico de anticorpos nessas mesmas amostras, a RT-PCR apresenta a vantagem na detecção do vírus circulante, ao contrário dos anticorpos, que poderiam ser resultantes de uma exposição antiga ao BVDV (Drew et al. 1999, Kozasa et al. 2005). No entanto, amostras de leite não estão disponíveis para vacas secas, novilhas, bezerros e rebanhos de corte (Seki et al. 2006).

A metodologia descrita por Pillars \& Grooms (2002) foi desenvolvida para a detecção do BVDV em rebanhos leiteiros. Para a análise de bezerros sentinelas em rebanhos de corte seria necessário o estabelecimento de outra estratégia de amostragem (Smith \& Grotelueschen 2004). Entretanto, nesse estudo, foram encontrados animais PI num rebanho de corte utilizando a metodologia desenvolvida para rebanhos leiteiros.

Levando em consideração o sistema de criação da maioria dos rebanhos de corte no Brasil, nos quais todas as categorias de animais são mantidas num mesmo grupo, tal metodologia poderia ser aplicada para tais rebanhos de corte. Afinal, se os animais PI estiverem presentes nesses rebanhos, a probabilidade dos demais animais entrarem em contato com eles é muito maior do que nos rebanhos leiteiros, que são separados em lotes de diferentes idades, e conseqüentemente o número de animais reagentes seria maior. Tanto é que, nos testes de VN empregados nas amostras de todos os animais do rebanho 4 , o qual era um rebanho de animais de corte, foram reagentes ao BVDV-1 e ao BVDV-2 acima de $94 \%$ das amostras analisadas (dados não mostrados).

A pesquisa de animais PI foi realizada apenas nos re- banhos que apresentaram resultados dentro dos parâmetros adotados por Pillars \& Grooms (2002), com exceção do rebanho 2, uma vez que não foi concedida a autorização do proprietário do rebanho para as colheitas pareadas. Pelos resultados obtidos nos testes de VN para o rebanho 2 (Quadro 1), e de acordo com os estudos realizados por Houe (1992, 1994) e Pillars \& Grooms (2002), sugere-se que a fonte de infecção do BVDV estaria presente neste rebanho na ocasião da realização da amostragem.

De todos os rebanhos analisados, 11 apresentaram bovinos reagentes ao BVDV $(1,2,3,4,5,7,16,17,20,21$ e 22), sendo sete rebanhos reagentes para ambos os genótipos (1, 2, 4, 5, 17, 20 e 21), dois rebanhos somente para o BVDV-1 (7 e 16), e dois rebanhos somente para o BVDV-2 (3 e 22) (Quadro 1). No entanto, a presença de bovinos reagentes na faixa etária analisada nesses rebanhos demonstrou que existiu o contato recente desses animais com o vírus (Seki et al. 2006), ou por meio de animais PI ou de animais TI (Smith \& Grotelueschen 2004).

No caso dos rebanhos 20 e 21, foram detectados bovinos reagentes com altos títulos de anticorpos, porém com número de bovinos insuficiente quando relacionados aos parâmetros utilizados na seleção. $\mathrm{O}$ baixo número de reagentes poderia ser devido ao período transitório entre a introdução da infecção no rebanho e o nascimento de animais PI (Houe 1994). Outra hipótese seria que os altos títulos de anticorpos encontrados nesses animais seriam resultantes de uma infecção recente e poucos animais do rebanho haviam tido contato com a fonte de infecção (Pillars \& Grooms 2002).

Por outro lado, nos outros dois rebanhos (1 e 17), dos quais foram colhidas amostras pareadas de todos os animais, não foram detectados animais PI. Entretanto, no teste de VN para o BVDV-1 e para o BVDV-2, mais de $80 \%$ dos bovinos no rebanho 1 foram reagentes e, no rebanho 17 , acima de $70 \%$ dos bovinos foram reagentes (dados não mostrados). Esses resultados justificam a quantidade de animais reagentes detectada na amostragem, bem como os altos títulos de anticorpos, sugerindo que a fonte de infecção do BVDV teria sido eliminada recentemente desses rebanhos (Houe 1999).

Entretanto, nesses mesmos rebanhos 1 e 17, a detecção de animais PI por meio de amostras de soro sangüíneo em bovinos com idade inferior a seis meses poderia estar comprometida, pois os anticorpos colostrais podem neutralizar o vírus livre na corrente circulatória e impedir o diagnóstico desses animais (Bezek \& Mechor 1992, Dubovi 1996, Saliki et al. 1997, Stokstad \& Loken 2002). Utilizando esse tipo de amostra, a confirmação da ausência de animais PI nesses rebanhos somente poderia ser estabelecida por meio de novos testes nos bezerros depois dos seis meses de idade, período em que os anticorpos colostrais não seriam mais detectáveis (Kelling 1990, Pillars \& Grooms 2002).

A persistência é a principal forma de manutenção do BVDV nos rebanhos bovinos e, conseqüentemente, na natureza (Brock 2003). A complexidade da enfermidade 
apresenta reflexos também no diagnóstico laboratorial, pois é necessário o conhecimento da patogenia da BVD para a interpretação dos resultados obtidos. Para o controle da BVD é essencial a detecção do animal PI no rebanho e o diagnóstico desses animais com base somente em sinais clínicos sugestivos não é real, pois muitos são saudáveis e não manifestam qualquer suspeita clínica.

Nesse contexto, estão inseridas as estratégias de amostragem que, mesmo apresentando limitações, podem direcionar o raciocínio clínico do médico veterinário ou até mesmo confirmar a suspeita de rebanhos infectados, a fim de que medidas concretas no controle da enfermidade possam ser adotadas. A pesquisa de anticorpos realizada num reduzido número de amostras de sangue, assim como foi feito neste estudo, poderia fornecer subsídios para o conhecimento do estado sanitário dos rebanhos bovinos brasileiros frente ao BVDV, considerando a realidade em que se encontram a grande maioria deles, tanto com relação às condições de biosseguridade encontradas, como também no que diz respeito aos menores custos para a obtenção do diagnóstico da infecção no rebanho.

\section{CONCLUSÕES}

Demonstrou-se a ocorrência de dois animais PI num rebanho bovino localizado no Estado de Minas Gerais, a partir da utilização de uma estratégia de amostragem para o diagnóstico de rebanhos infectados pelo BVDV.

A estratégia de amostragem adotada para a detecção de animais $\mathrm{Pl}$ em rebanhos leiteiros foi suficiente para a detecção de animais $\mathrm{PI}$ em um rebanho de corte.

Agradecimentos.- Os autores agradecem à Fundação de Apoio e Pesquisa do Estado de São Paulo (FAPESP), pelo financiamento desta pesquisa (Proc. 04/06800-0 e 06/59757-0) e ao Prof. Dr. Eduardo Furtado Flores, da Universidade Federal de Santa Maria, que gentilmente cedeu as estirpes citopatogênicas do BVDV-1 (Singer) e do BVDV-2 (VS-253) para a realização das reações de VN.

\section{REFERÊNCIAS}

Baker J.C. 1987. Bovine viral diarrhea virus: a review. J. Am. Vet. Med. Assoc. 190:1449-1458.

Bezek D.M. \& Mechor G.D. 1992. Identification and eradication of bovine viral diarrhea virus in a persistently infected dairy herd. J. Am. Vet. Med. Assoc. 201:580-586.

Bolin S.R. 1990. The current understanding about the pathogenesis and clinical forms of BVD. Vet. Med. 85:1.124-1.132.

Boom R., Sol C.J.A., Salimans M.M.M., Jansen C.L., Wertheimdillen P.M.E. \& Noordaa J. 1990. Rapid and simple method for purification of nucleics acids. J. Clin. Microbiol. 28:495-503.

Brock K.V. 1995. Diagnosis of bovine viral diarrhea virus infections. Vet. Clin. North Am., Food Anim. Pract. 11:549-561.

Brock K.V. 2003. The persistence of bovine viral diarrhea virus. Biologicals 31:133-135.

Brownlie J. 1990. Pathogenesis of mucosal disease and molecular aspects of bovine virus diarrhoea virus. Vet. Microbiol. 23:371-382.

Deregt D. 2005. Introduction and history, p.3-33. In: Goyal S.M. \& Ridpath J.F. (Eds), Bovine Viral Diarrhea Virus. Blackwell Publishing, lowa.

Dias F.C. \& Samara S. 2003. Detecção de anticorpos contra o vírus da diarréia viral bovina no soro sangüíneo, no leite individual e no leite de conjunto em tanque de expansão de rebanhos não vacinados. Braz. J. Vet. Res. Anim. Sci. 40:161-168.

Drew T.W., Yapp F. \& Paton D.J. 1999. The detection of bovine viral diarrhoea virus in bulk milk samples by the use of a single-tube RTPCR. Vet. Microbiol. 64:145-154.

Dubovi E.J. 1996. Laboratory diagnosis of bovine viral diarrhea virus infections. Vet. Med. 91:867-872.

Dubovi E.J. 1998. Bovine viral diarrhea virus. Anais Simpósio Internacional sobre Herpesvirus Bovino e Vírus da Diarréia Viral Bovina, Santa Maria, RS, p.1-19.

Houe H. 1992. Serological analysis of a small herd sample to predict presence or absence of animals persistently infected with bovine viral diarrhea virus (BVDV) in dairy herds. Res. Vet. Sci. 53:320-323.

Houe H. 1993. Survivorship of animals persistently infected with bovine virus diarrhoea virus (BVDV). Prev. Vet. Med. 15:275-283.

Houe H. 1994. Bovine virus diarrhea virus: Detection of Danish dairy herds with persistently infected animals by means of a screening test of ten young stock. Prev. Vet. Med. 19:241-248.

Houe H. 1995. Epidemiology of bovine viral diarrhea virus. Vet. Clin. North Am., Food Anim. Pract. 11:521-547.

Houe H. 1999. Epidemiological features and economical importance of bovine virus diarrhoea virus (BVDV) infections. Vet. Microbiol. 64:89107.

Kelling C.L., Stine L., Rump K. \& Parker R. 1990. Investigation of bovine viral diarrhea virus infections in a range beef cattle herd. J. Am. Vet. Med. Assoc. 197:589-593.

Kozasa T., Tajima M., Yasutomi I., Sano K., Ohashi K. \& Onuma M. 2005. Relationship of bovine viral diarrhea virus persistent infection to incidence of diseases on dairy farms base on bulk tank milk test by RT-PCR. Vet. Microbiol. 106:41-47.

Lieber-Tenorio E.M. 2005. Pathogenesis, p.121-143. In: Goyal S.M. \& Ridpath J.F. (Eds), Bovine Viral Diarrhea Virus. Blackwell Publishing, lowa.

OIE. 2008. Manual of Diagnostic Testes and Vaccines for Terrestrial Animals. $6^{\text {th }}$ ed. World Organization for Animal Health, Paris. 1343p.

Pillars R.B. \& Grooms D.L. 2002. Serologic evaluation of five unvaccinated heifers to detect herds that have cattle persistently infected with bovine viral diarrhea virus. Am. J. Vet. Res. 63:499505.

Pilz D., Alfieri A.F. \& Alfieri A.A. 2005. Comparação de diferentes protocolos para a detecção do vírus da diarréia viral bovina pela RTPCR em grupos de sangue total e de soro sangüíneo, artificialmente contaminados. Semina 26:219-228.

Ridpath J.F. 2010. Bovine Viral Diarrhea Virus: Global status. Vet. Clin. North Am., Food Anim. Pract. 26:105-121.

Saliki J.T., Fulton R.W., Hull S.R. \& Dubovi E.J. 1997. Microtiter virus isolation and enzyme immunoassays for detection of bovine viral diarrhea virus in cattle serum. J. Clin. Microbiol 35:803-807.

Sandvik T. 1999. Laboratory diagnostic investigations for bovine viral diarrhoea virus infections in cattle. Vet. Microbiol. 64:123-134.

Seki Y., Seimiyia Y.N., Yaegashi G. \& Sato C. 2006. Identification of herds with cattle persistently infected with bovine viral diarrhea virus by virological evaluation of three calves. J. Vet. Med. Sci. 68:255258.

Smith D.V. \& Grotelueschen D.M. 2004. Biosecurity and biocontainment of bovine viral diarrhea virus. Vet. Clin. North Am., Food Anim. Pract. 20:131-149.

Stokstad M. \& Loken T. 2002. Pestivirus in cattle: experimentally induced persistent infection in calves. J. Vet. Med. B 49:494-501.

Thrusfield M. 1986. Veterinary Epidemiology. Butterworth, London. 280p.

Weinstock D., Bhudevi B. \& Castro A.E. 2001. Single-tube singleenzyme reverse transcriptase PCR assay for detection of bovine viral diarrhea virus in pooled bovine serum. J. Clin. Microbiol. 39:343346. 